\title{
Isolation and Structure of a Galactocerebroside from the Sea Cucumber Bohadschia argus
}

\author{
Yuriko Ikeda, ${ }^{a, b}$ Masanori Inagaki, ${ }^{a}$ Koji Yamada,,${ }^{a}$ Xiao Wen Zhang, ${ }^{a}$ Bo Zhang, ${ }^{a}$ \\ Tomofumi Miуamoto, ${ }^{a}$ and Ryuichi Higuchi ${ }^{*}, a$ \\ ${ }^{a}$ Graduate School of Pharmaceutical Sciences, Kyushu University; 3-1-1 Maidashi, Higashi-ku, Fukuoka 812-8582, \\ Japan: and ${ }^{b}$ Faculty of Pharmaceutical Sciences, Nagasaki International University; 2825-7 Huis Ten Bosch, Sasebo, \\ Nagasaki 859-3298, Japan. $\quad$ Received November 21, 2008; accepted January 8, 2009; published online January 8, 2009
}

A galactocerebroside (BAC-4-4a) was obtained from its parent galactocerebroside molecular species (BAC4) by using two types of reversed-phase HPLC column. The parent cerebroside BAC-4 has been isolated from less polar lipid fraction of $\mathrm{CHCl}_{3} / \mathrm{MeOH}$ extract of sea cucumber Bohadschia argus, together with known typical types of glucocerebroside molecular species. The structure of BAC-4-4a was determined on the basis of chemical and spectroscopic evidences as 1 - $O$ - $(\beta$-D-galactopyranosyl)-(2S,3R,4E)-2[(2'R,15'Z)-2-hydroxytetracosenoylamino]-4-heptadecene-1,3-diol. This is the first report of isolation and structure determination of galactocerebroside from sea cucumber.

Key words glycosphingolipid; galactocerebroside; sea cucumber; Bohadschia argus

In our ongoing search for biologically active glycosphingolipids (GSLs) from sea cucumbers, we have isolated numerous cerebrosides and gangliosides. ${ }^{1-7)}$ Continuing the previous studies, three cerebroside molecular species (BAC1 , BAC-2 and BAC-3) was obtained from the less polar lipid fraction of $\mathrm{CHCl}_{3} / \mathrm{MeOH}$ extract of sea cucumber Bohadschia argus (Janomenamako in Japanese). The structures of BAC-1, BAC-2 and BAC-3 could be determined by hitherto reported chemical and spectroscopic methods ${ }^{2,4,5)}$ as the molecular species of typical types of glucocerebrosides, ${ }^{2,45}$ namely, a sphingosine-type $\beta$-glucocerebroside possessing non-hydroxy fatty acid (BAC-1), a sphingosine-type $\beta$-glucocerebroside possessing 2-hydroxy fatty acid (BAC-2), and phytosphingosine-type $\beta$-glucocerebroside possessing 2-hydroxy fatty acid (BAC-3), respectively (data not shown), as revealed in Fig. 1. However, in the course of structure determination of BAC-2, it was found that BAC-2 contained a small amount of galactocerebroside isomer. In this paper, we report on the isolation and structure determination of galactocerebroside, rare in the phylum echinoderms, from the sea cucumber B. argus.

The less polar lipid fraction, which was obtained from $\mathrm{CHCl}_{3} / \mathrm{MeOH}$ extract of whole bodies of $B$. argus, was subjected to silica gel column chromatography repeatedly to give a glucocerebroside molecular species BAC-2. BAC-2 was further purified by silica gel column chromatography using a complex solvent system $\left(\mathrm{AcOEt} / \mathrm{CHCl}_{3} / \mathrm{MeOH} / \mathrm{H}_{2} \mathrm{O}\right)$ to give a minor component BAC-4.

Structure of Galactocerebroside Molecular Species BAC-4 Positive-ion fast-atom bombardment (FAB) mass spectrum of BAC-4 exhibited a series of molecular ion peaks. In its ${ }^{13} \mathrm{C}-\mathrm{NMR}$ spectrum, BAC-4 revealed the characteristic signals of sphingosine-type $\beta$-galactocerebroside possessing 2-hydroxy fatty acid (Fig. 2, Table 1). ${ }^{2,8)}$ Furthermore, BAC-4 was thought to possess normal- and iso-types ${ }^{9)}$ of side chains same as BAC- 2 on the basis of the carbon atom signals of the terminal methyl group (Table 1).

When BAC-4 was methanolyzed with methanolic hydrochloric acid, a mixture of fatty acid methyl ester (FAM) was obtained together with a mixture of long chain base
(LCB). Gas chromatography-mass spectrometry (GC-MS) analysis of FAMs from BAC-4 showed the existence of four components, which were identified as methyl 2-hydroxydocosanoate (FAM-1), methyl 2-hydroxytricosanoate (FAM-2), methyl 2-hydroxytetracosenoate (FAM-3), methyl 2-hydroxytetracosanoate (FAM-4). On the other hand, GC-MS analysis of the trimethylsilyl (TMS) derivatives of the LCBs from BAC-4 showed the presence of four kinds of component: 2amino-1,3-dihydroxy-4-hexadecene (LCB-1), 2-amino-1,3dihydroxy-4-heptadecene (LCB-2) and 2-amino-1,3-dihydroxy-4-octadecene (LCB-3).

Therefore, BAC-4 is sphingosine-type galactocerebroside molecular species composed of the aforementioned fatty
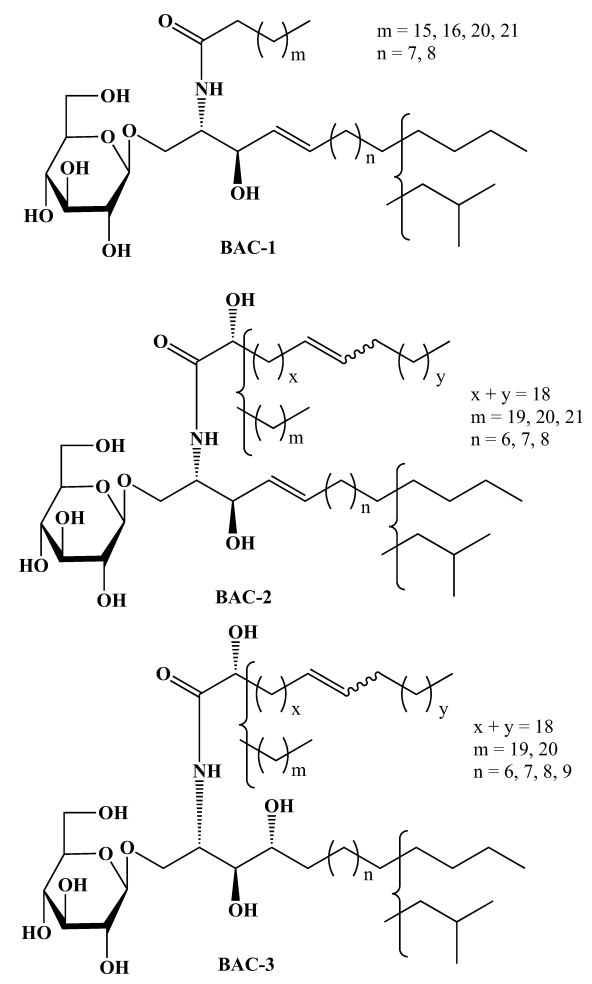

Fig. 1. Structure of BAC-1, BAC-2 and BAC-3 


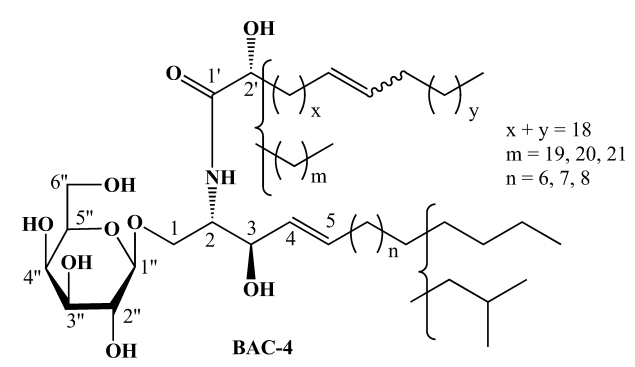

Fig. 2. Structure of BAC-4

Table $1 .{ }^{13} \mathrm{C}$-NMR Spectral Data ( $\delta$ Values) of Cerebrosides in $\mathrm{C}_{5} \mathrm{D}_{5} \mathrm{~N}$

\begin{tabular}{|c|c|c|c|}
\hline $\mathrm{C}$ & & BAC-4 & BAC-4-4a \\
\hline \multicolumn{4}{|l|}{ Ceramide } \\
\hline 1 & (t) & 70.2 & 70.1 \\
\hline 2 & (d) & 54.5 & 54.5 \\
\hline 3 & (d) & 72.3 & 72.3 \\
\hline 4 & (d) & 131.8 & 131.7 \\
\hline 5 & (d) & 132.7 & 132.7 \\
\hline $1^{\prime}$ & (s) & 175.6 & 175.6 \\
\hline $2^{\prime}$ & (d) & 72.5 & 72.4 \\
\hline$=\underline{\mathrm{CHCH}}_{2}-$ & (d) & 130.2 & 130.2 \\
\hline$=\overline{\mathrm{C}} \mathrm{HCH}_{2}-$ & $(t)$ & & 27.5 \\
\hline$-\mathrm{CH}_{2} \mathrm{CH}_{2}{ }_{\mathrm{C}} \mathrm{H}_{3}$ & (q) & 14.2 & 14.2 \\
\hline$-\mathrm{CH}\left(\mathrm{CH}_{3}\right)_{2}$ & (q) & 22.8 & 22.7 \\
\hline \multicolumn{4}{|l|}{ Sugar moiety } \\
\hline $1^{\prime \prime}$ & (d) & 106.2 & 106.1 \\
\hline $2^{\prime \prime}$ & (d) & 72.5 & 72.5 \\
\hline $3^{\prime \prime}$ & (d) & 75.3 & 75.2 \\
\hline $4^{\prime \prime}$ & (d) & 70.3 & 70.2 \\
\hline $5^{\prime \prime}$ & (d) & 77.1 & 77.0 \\
\hline $6^{\prime \prime}$ & (t) & 62.4 & 62.3 \\
\hline
\end{tabular}

acids and long chain bases (Fig. 2).

Isolation and Structure of Galactocerebroside BAC-44a from BAC-4 Isolation of homogeneous galactocerebroside was conducted from the galactocerebroside molecular species BAC-4. The reversed-phase (C18) HPLC of BAC-4 gave three major fractions, BAC-4-4, BAC-4-6 and BAC-4-8, each behaving as pure compounds in HPLC. Both BAC-4-6 and BAC-4-8 showed the single molecular ion peaks as $[\mathrm{M}+\mathrm{Na}]^{+}$in the positive-ion FAB mass spectra, however BAC-4-4 revealed two molecular ion peaks. BAC-4-4 was further separated by another reversed-phase (cholesteryl) HPLC to give two components, BAC-4-4a and BAC-4-4b, both of which revealed single molecular ion peaks in their positive-ion FAB mass spectra. When these four compounds, believed to be pure substances, are methanolayzed, a single FAM is detected from BAC-4-4a, however diverse FAMs are obtained from the other three compounds. Accordingly, only one compound, BAC-4-4a, can be homogeneous cerebroside. BAC-4-4a, a component of BAC-4 as shown in Table 1, is composed of 2-hydroxytetracosenoic acid and $\mathrm{C}_{17}$-sphingosine (LCB-2) as its cerebroside moiety from the result of methanolysis. The location and geometric isomerism of the double bond in the fatty acyl moiety was determined as follows. Dimethyl disulfide (DMDS) derivative ${ }^{10,11)}$ of FAM from BAC-4-4a showed remarkable fragment-ion peaks at $m / z: 317$ and 173 in the electron impact (EI) mass spectrum, due to the cleavage of the bonds between the carbons bearing the methylthio groups (Fig. 3). The EI mass spectral data in-

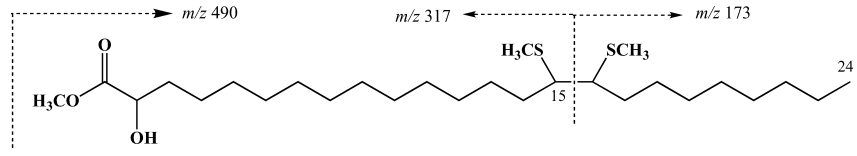

Fig. 3. Mass Fragmentation of DMDS Derivative of FAM from BAC-4-4a

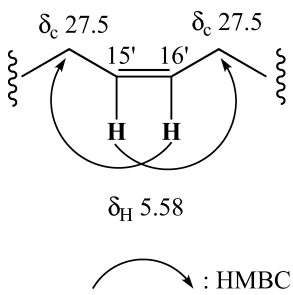

Fig. 4. HMBC Correlations of the Fatty Acyl Moiety of BAC-4-4a

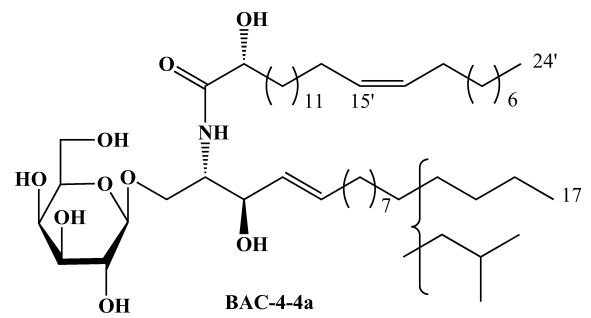

Fig. 5. Structure of BAC-4-4a

dicated that the double bond in the fatty acyl moiety of BAC$4-4$ a was located at C-15. The geometry $(Z)$ of the double bond was determined from the $\delta$ value (27.5) of the allylic carbon atoms obtained from HMBC spectrum of BAC-4-4a (Fig. 4), since allylic carbon signals of $Z$ - and $E$-isomer are observed at $\delta$ ca. $26-27 \mathrm{ppm}$ and $\delta$ ca. 31-32 ppm, respectively. ${ }^{12)}$ The relative configuration of the ceramide moiety of BAC-4-4a is proposed as shown in Fig. 5 by comparison of the ${ }^{13} \mathrm{C}$-NMR spectral data of BAC-4-4a with that of BAC-4 whose relative configuration has already been known as shown in Fig. 2 (Table 1). The optical rotations of BAC-4$4 \mathrm{a}\left[+12.1^{\circ}\right.$, in $\left.\mathrm{CHCl}_{3} / \mathrm{MeOH}(1: 1)\right]$ and the synthetic $\beta$-Dgalactocerebroside composed of $(2 S, 3 R, 4 E)$-sphingosine and (2R)-2-hydroxy fatty acid $\left[+8.5^{\circ} \text {, in } \mathrm{CHCl}_{3} / \mathrm{MeOH}(1: 1)\right]^{13)}$ suggested that BAC-4-4a possessed the same absolute configuration as the synthetic compound for the core structure (C-2, C-3, C-2' and galactose). On the basis of above evidences, the structure of BAC-4-4a was proposed to be $1-O$ ( $\beta$-D-galactopyranosyl)-( $2 S, 3 R, 4 E)-2\left[\left(2^{\prime} R, 15^{\prime} Z\right)-2\right.$-hydroxytetracosenoylamino]-4-heptadecene-1,3-diol as shown in Fig. 5.

Many kinds of glucocerebrosides have been obtained from echinoderms. However, as for the galactocerebrosides from echinoderms, only several kinds of the cerebrosides have been obtained from the starfish Stellaster equestris, ${ }^{8)}$ Culcita novaeguineae, ${ }^{14)}$ and Oreaster reticulatus. ${ }^{15)}$ Especially as regarding the finding of the galactocerebroside (BAC-4-4a) from sea cucumber, we believe that this study has been made for the first time.

\section{Experimental}

Melting points were determined on a micro melting point apparatus (Yanako MP-3) without correction. Optical rotations were measured with a Jasco DIP-370 digital polarimeter at $25^{\circ} \mathrm{C}$. IR spectra were obtained on a 
Jasco FT/IR-4200 spectrometer. NMR spectra were recorded on Varian Unity Plus-400/500 spectrometer $\left({ }^{1} \mathrm{H}: 400 / 500 \mathrm{MHz},{ }^{13} \mathrm{C}: 100 / 125 \mathrm{MHz}\right)$. Positiveion FAB mass spectra were acquired JOEL JMS-SX-102 mass spectrometer (xenon atom beam; matrix, $m$-nitrobenzyl alcohol $+\mathrm{NaCl}$ ). GC-MS were taken with a Shimazu QP5050A [EI mode; ionizing potential, $70 \mathrm{eV}$; column, NEUTRA BOND-5 $(0.25 \mathrm{~mm} \times 30 \mathrm{~m}$; GL Science Inc., Tokyo, Japan $)$; carrier gas, He]. HPLC was carried out using COSMOSIL $5 \mathrm{C}_{18}$-AR-II $(4.6 \mathrm{~mm} \times 250 \mathrm{~mm})$ and COSMOSIL Cholester $(4.6 \mathrm{~mm} \times 250 \mathrm{~mm})$ as columns, PU-980 Intelligent HPLC pump (Jasco), and an RI-930 Intelligent HPLC detector (Jasco).

Separation of BAC-4 Whole bodies of sea cucumber Bohadschia argus (207.3 kg), which were collected at Zanpamisaki, Okinawa (Japan), were chopped and extracted with $\mathrm{CHCl}_{3} / \mathrm{MeOH}(1: 4, \mathrm{v} / \mathrm{v})$ followed by further extraction with $\mathrm{CHCl}_{3} / \mathrm{MeOH}(1: 2, \mathrm{v} / \mathrm{v})$. The combined extracts were concentrated in vacuo to give an aqueous solution, which was extracted with $n$ hexane three times. The aqueous phase was extracted with $n-\mathrm{BuOH}$, and the $n$ - $\mathrm{BuOH}$ phase was concentrated in vacuo to give an extractive, which was partitioned between $\mathrm{H}_{2} \mathrm{O}$ and $\mathrm{AcOEt} / n-\mathrm{BuOH}(3: 1, \mathrm{v} / \mathrm{v})$. The organic layer was concentrated in vacuo to give the residue (less polar lipid fraction). The less polar lipid fraction was chromatographed on silica gel (solvent $\mathrm{CHCl}_{3}$ / $\mathrm{MeOH} / \mathrm{H}_{2} \mathrm{O}, 19: 1: 0$ to $6: 4: 1$ ) followed by Sephadex LH-20 (solven $\left.\mathrm{CHCl}_{3} / \mathrm{MeOH}, 1: 1\right)$ to give cerebroside fraction. The cerebroside fraction was further separated by silica gel column chromatography (solvent $\mathrm{CHCl}_{3} / \mathrm{MeOH} / \mathrm{H}_{2} \mathrm{O}, 9: 1: 0.05$ to $\left.8: 2: 0.1\right)$ to give BAC-2 $[R f=0.17$, silica gel TLC, solvent $\left.\mathrm{CHCl}_{3} / \mathrm{MeOH} / \mathrm{H}_{2} \mathrm{O}(9: 1.5: 0.05)\right]$. BAC-2 was purified by silica gel column chromatography using AcOEt $/ \mathrm{CHCl}_{3} / \mathrm{MeOH} / \mathrm{H}_{2} \mathrm{O}(8: 2$ : $0.5: 0.05$ to $0: 6: 4: 1)$ as a solvent to give BAC-4 $(48 \mathrm{mg} ; R f=0.35)$ together with genuine BAC-2 $(89 \mathrm{mg} ; R f=0.43)$ [solvent $\mathrm{AcOEt} / \mathrm{CHCl}_{3} /$ $\left.\mathrm{MeOH} / \mathrm{H}_{2} \mathrm{O}(8: 2: 2: 0.1)\right]$

BAC-4: Amorphous powder. IR $(\mathrm{KBr}) \mathrm{cm}^{-1}: 3323(\mathrm{OH}), 1661,1557$ (amide). Positive-ion FAB-MS $m / z: 800-880[\mathrm{M}+\mathrm{Na}]^{+}$series. ${ }^{1} \mathrm{H}-\mathrm{NMR}$ $\left(\mathrm{C}_{5} \mathrm{D}_{5} \mathrm{~N}\right) \delta: 0.87$ (terminal methyl groups $\left.{ }^{16)}\right), 4.81(1 \mathrm{H}, \mathrm{d}, J=7.8 \mathrm{~Hz}$, galactose $\mathrm{H}-1), 8.32(1 \mathrm{H}, \mathrm{d}, J=8.7 \mathrm{~Hz}, \mathrm{NH}) .{ }^{13} \mathrm{C}$-NMR: see Table 1.

Methanolysis of BAC-4 BAC-4 $(0.5 \mathrm{mg})$ was heated with $5 \% \mathrm{HCl}$ in $\mathrm{MeOH}(1 \mathrm{ml})$ at $90^{\circ} \mathrm{C}$ for $7 \mathrm{~h}$. The reaction mixture was then extracted with $n$-hexane, and the extract was concentrated to give a mixture of FAM for GC-MS analysis. The MeOH layer was neutralized with $\mathrm{Ag}_{2} \mathrm{CO}_{3}$, filtrated, and the filtrate was concentrated in vacuo to give a mixture of $\mathrm{LCB}$.

GC-MS Analysis of FAM from BAC-4 A FAM mixture from BAC-4 was subjected to GC-MS [column temperature $180-320^{\circ} \mathrm{C}$ (rate of temperature increases $4{ }^{\circ} \mathrm{C} / \mathrm{min}$ )]. The results were as follows: FAM-1 (methyl 2hydroxydocosanoate), $t_{\mathrm{R}}[\mathrm{min}]$ (ratio of peak area) $=24.6(29.9), \mathrm{m} / \mathrm{z}: 370$ $\left(\mathrm{M}^{+}\right), 311(\mathrm{M}-59)^{+}$; FAM-2 (methyl 2-hydroxytricosanoate), $t_{\mathrm{R}}=26.5$ (25.9), $m / z$ : $384\left(\mathrm{M}^{+}\right), 325(\mathrm{M}-59)^{+}$; FAM-3 (methyl 2-hydroxytetracosenoate), $t_{\mathrm{R}}=27.9(25.0), m / z: 396\left(\mathrm{M}^{+}\right), 337(\mathrm{M}-59)^{+}$; FAM-4 (methyl 2-hydroxytetracosanoate), $t_{\mathrm{R}}=28.3(19.2), \mathrm{m} / \mathrm{z}: 398\left(\mathrm{M}^{+}\right), 339(\mathrm{M}-59)^{+}$.

GC-MS Analysis of TMS Ethers of LCB from BAC-4 A LCB mixture from BAC-4 was heated with 1-(trimethylsilyl)imidazole/pyridine $(1: 1$, $\mathrm{v} / \mathrm{v}$ ) for $15 \mathrm{~min}$ at $80^{\circ} \mathrm{C}$ and the reaction mixture (TMS esters) were analyzed by GC-MS [column temperature $180-320^{\circ} \mathrm{C}$ (rate of temperature increases $8^{\circ} \mathrm{C} / \mathrm{min}$ )]. The results were as follows: LCB-1 (2-amino-1,3-dihydroxy-4-hexadecene), $t_{\mathrm{R}}[\mathrm{min}]$ (ratio of peak area) $=11.6(24.4), \mathrm{m} / \mathrm{z}: 312$ $(\mathrm{M}-103)^{+}, 283(\mathrm{M}-132)^{+}$; LCB-2 (2-amino-1,3-dihydroxy-4-heptadecene), $t_{\mathrm{R}}=12.3,12.4(59.5,4.1), \mathrm{m} / z: 326(\mathrm{M}-103)^{+}, 297(\mathrm{M}-132)^{+}$; LCB-3 (2amino-1,3-dihydroxy-4-octadecene), $t_{\mathrm{R}}=13.3(12.0), \mathrm{m} / \mathrm{z}: 340(\mathrm{M}-103)^{+}$, $311(\mathrm{M}-132)^{+}$

Isolation of Galactocerebroside Component BAC-4-4a from BAC-4 Reversed-phase HPLC of BAC-4 [column COSMOSIL 5C 18 -AR-II; solvent $\mathrm{MeOH}$; flow rate $1 \mathrm{ml} / \mathrm{min}$ ] showed nine peaks. Using this condition, $30 \mathrm{mg}$ of BAC-4 was separated by HPLC to give three major fractions, 4 (BAC-4-4, $3.1 \mathrm{mg}$ ), 6 (BAC-4-6, $0.9 \mathrm{mg}$ ) and 8 (BAC-4-8, $2.4 \mathrm{mg}$ ). Fraction 4 was successively separated by using reversed-phase HPLC [column COSMOSIL Cholester; solvent $\mathrm{MeOH}$; flow rate $1 \mathrm{ml} / \mathrm{min}$ ] to yield two compounds, BAC-4-4a $(0.7 \mathrm{mg})$ and BAC-4-4b $(1.5 \mathrm{mg})$.

BAC-4-4a: Amorphous powder, $\mathrm{mp} 200-205^{\circ} \mathrm{C} .[\alpha]_{\mathrm{D}}+12.1^{\circ}[c=0.18$, $\left.\mathrm{CHCl}_{3} / \mathrm{MeOH}(1: 1)\right],[\alpha]_{\mathrm{D}}+30.6^{\circ}(c=0.18, n$-PrOH $)$. Positive-ion FABMS $m / z: 834[\mathrm{M}+\mathrm{Na}]^{+} .{ }^{1} \mathrm{H}-\mathrm{NMR}\left(\mathrm{C}_{5} \mathrm{D}_{5} \mathrm{~N}\right) \quad \delta: 0.85$ (terminal methyl groups $\left.^{16)}\right), 4.81(1 \mathrm{H}, \mathrm{d}, J=7.8 \mathrm{~Hz}$, galactose $\mathrm{H}-1), 5.58(2 \mathrm{H}, \mathrm{m}, \mathrm{CH}=\mathrm{CH}), 8.29$
$(1 \mathrm{H}, \mathrm{d}, J=8.5 \mathrm{~Hz}, \mathrm{NH}) .{ }^{13} \mathrm{C}-\mathrm{NMR}$ : see Table 1 .

BAC-4-4b: Amorphous powder. Positive-ion FAB-MS m/z: 808 $[\mathrm{M}+\mathrm{Na}]^{+}$.

BAC-4-6: Amorphous powder. Positive-ion FAB-MS m/z: $822[\mathrm{M}+\mathrm{Na}]^{+}$.

BAC-4-8: Amorphous powder. Positive-ion FAB-MS $m / z: 836[\mathrm{M}+\mathrm{Na}]^{+}$.

Methanolysis of BAC-4-4a, BAC-4-4b, BAC-4-6 and BAC-4-8 In the same manner as described for BAC-4, BAC-4-4a, BAC-4-4b, BAC-4-6 and BAC-4-8 were methanolyzed. The FAM from each compound was subjected to GC-MS under the same conditions as for BAC-4 and the following FAMs were detected: BAC-4-4a (FAM-3), BAC-4-4b (FAM-1, FAM-2), BAC-4-6 (FAM-1, FAM-2 and FAM-4), BAC-4-8 (FAM-1, FAM-2 and FAM-4).

GC-MS Analysis of TMS Ethers of LCB from BAC-4-4a The LCB from BAC-4-4a, which was obtained by methanolysis, was treated in the same way as BAC-4, and the reaction mixture (TMS ester) was analyzed using GC-MS under the same conditions as for BAC-4, and LCB-2 (2amino-1,3-dihydroxy-4-heptadecene) was detected.

DMDS Derivatives of BAC-4-4a FAM The FAM from BAC-4-4a (methyl 2-hydroxytetracosenoate) was dissolved in carbon disulfide $(0.2 \mathrm{ml})$ in a sealed small-volume vial. DMDS $(0.2 \mathrm{ml})$ and iodine $(1.0 \mathrm{mg})$ were added to the solution. The resulting mixture was kept at $60^{\circ} \mathrm{C}$ for $40 \mathrm{~h}$. The reaction was subsequently quenched with aqueous $\mathrm{Na}_{2} \mathrm{~S}_{2} \mathrm{O}_{3}(5 \%)$, and the mixture was extracted with $n$-hexane. The extract was concentrated, and the residue (DMDS derivative) was analyzed by GC-MS [column temperature $180-320^{\circ} \mathrm{C}$ (rate of temperature increases $8^{\circ} \mathrm{C} / \mathrm{min}$ )]: DMDS derivative of BAC-4-4a FAM, $t_{\mathrm{R}}[\mathrm{min}]=25.6, \mathrm{~m} / \mathrm{z}: 490\left(\mathrm{M}^{+}\right), 317(\mathrm{M}-173)^{+}, 173(\mathrm{M}-$ $317)^{+}$

Acknowledgements We thank Mr. Y. Tanaka and Ms. T. Seki of the Faculty of Pharmaceutical Sciences, Kyushu University, for the NMR measurements. This work was supported in part by a Grant-in-Aid for Scientific Research (No. 16510163, 18510187) from the Japan Society for the Promotion of Science, which are gratefully acknowledged.

\section{References and Notes}

1) Yamada K., Matsubara R., Kaneko M., Miyamoto T., Higuchi R., Chem. Pharm. Bull., 49, 447-452 (2001).

2) Yamada K., Sasaki K., Harada Y., Isobe R., Higuchi R., Chem. Pharm. Bull., 50, 1467-1470 (2002).

3) Yamada K., Hamada A., Kisa F., Miyamoto T., Higuchi R., Chem. Pharm. Bull., 51, 46-52 (2003).

4) Kisa F., Yamada K., Kaneko M., Inagaki M., Higuchi R., Chem. Pharm. Bull., 53, 382-386 (2005).

5) Yamada K., Wada N., Onaka H., Matsubara R., Isobe R., Higuchi R., Chem. Pharm. Bull., 53, 788-791 (2005).

6) Kisa F., Yamada K., Miyamoto T., Inagaki M., Higuchi R., Chem. Pharm. Bull., 54, 982-987 (2006).

7) Kisa F., Yamada K., Miyamoto T., Inagaki M., Higuchi R., Chem. Pharm. Bull., 54, 1293-1298 (2006).

8) Higuchi R., Harano Y., Mitsuyuki M., Isobe R., Yamada K., Miyamoto T., Liebigs Ann., 1996, 593-599 (1996).

9) Normal means the straight chain $\left[-\mathrm{CH}_{2} \mathrm{CH}_{2} \mathrm{CH}_{3}\right]$, iso means the blanched chain possessing a methyl group on the second carbon atom of the terminal group $\left[-\mathrm{CH}_{2} \mathrm{CH}\left(\mathrm{CH}_{3}\right)_{2}\right]$.

10) Vinccenti M., Guglielmitti G., Cassani G., Tonini C., Anal. Chem., 59, 694-699 (1987).

11) Scribe P., Guezennec J., Dagaut J., Pepe C., Saliot A., Anal. Chem., 60, 928-931 (1988).

12) Fusetani N., Yasumuro K., Matsunaga S., Hirota H., Tetrahedron Lett., 30, 6891-6894 (1989)

13) Koike K., Sugimoto M., Nakahata Y., Ogawa T., Carbohydr. Res., 162, 237-246 (1987)

14) Inagaki M., Nakata T., Higuchi R., Chem. Pharm. Bull., 54, 260-261 (2006).

15) Costantino V., Rosa C. D., Fattorusso E., Imperatore C., Mangoni A., Irace C., Maffettone C., Capasso D., Malorni L., Palumbo R., Pedone C., Eur. J. Org. Chem., 2007, 5277-5283 (2007).

16) Signals due to terminal methyl groups of normal-and iso-types of side chains showed the same chemical shift values. 